\title{
Kajian Etnobotani dan Reproduksi Tumbuhan Obat Di Desa Jagalan Kecamatan Kwanyar Kabupaten Bangkalan
}

\author{
Riadul Jannah ${ }^{1 *}$, Ari Hayati ${ }^{2}$, Tintrim Rahayu ${ }^{3}$ \\ 1,2,P Program Studi Biologi Fakultas Matematika dan Ilmu Pengetahuan Alam Universitas Islam Malang, Indonesia \\ Koresponden Penulis : wahyuria847@gmail.com
}

\begin{abstract}
ABSTRAK
Etnobotani merupakan ilmu botani yang mempelajari tentang pemanfaatan tumbuhan dalam keperluan hidup sehari-hari dan adat suku bangsa. Pemanfaatan tumbuhan sebagai obat tradisional (herbal) telah di kenal sejak lama oleh masyarakat di Desa jagalan. Penelitian ini bertujuan untuk mengidentifikasi tumbuhan obat, pemanfaatan tumbuhan obat, dan reproduksi tumbuhan obat oleh masyarakat Desa Jagalan Kecamatan Kwanyar Kabupaten Bangkalan. Penelitian ini dilakukan pada Bulan Mei-Juni 2019 dengan menggunakan metode kualitatif. Metode kualitatif digunakan untuk mengumpulkan data melalui wawancara. Responden dipilih menggunakan purposive sampling yaitu anggota masyarakat yang mengetahui tumbuhan obat khususnya kepada orang tua dengan rentang usia (35-80 tahun). Penelitian menunjukkan data rata-rata responden yang ditemui 150 responden. Ada 14 jenis tumbuhan obat yang dimanfaatkan di Desa Jagalan, yaitu Bingbuluh (Belimbing wuluh), jeih (jahe). Kencur (kencor), Sere (Sirih), Molabek Temulawak), Moereng (Temuireng), Binahong, Meronggih (Kelor), Konyek (kunyit), Mores (Sirsak), Jembuh (Jambu biji), Jeruk Porot (Jeruk nipis), Kodduk (Mengkudu), Blimbing (Belimbing). Reproduksi dibagi menjadi dua bagian yaitu aseksual dan seksual, bingbuluh, meronggih, jembuh, jeruk porot,mores, kodduk, dan blimbing termasuk pada reproduksi generative dan vegetatf, jeih, kencor, molabek, moereng, binahong, dan konyek termasuk reproduksi rhizoma (rimpang, akar tinggal) merupakan batang yang tumbuh menjalar secara horizontal di dalam tanah menyerupai akar dan kemudian pada sirih termasuk pada reproduksi vegetatif buatan yang dengan cara mencangkok dan merunduk.
\end{abstract}

Kata kunci: Etnobotani, Jagalan, Konservasi, Tumbuhan obat

\begin{abstract}
Ethnobotany is a botanical science that studies the use of plants in the needs of daily life and tribal customs. The use of plants as traditional medicine (herbal) has been known for a long time by the people in Desa Jagalan. This study aims to identify medicinal plants, utilization of medicinal plants, and reproduction of medicinal plants by the people of Jagalan Village, Kwanyar District, Bangkalan Regency. This research was conducted in May-2019 using qualitative methods. Qualitative methods are used to collect data through interviews. Respondents were selected using purposive sampling, namely community members who knew about medicinal plants, especially for parents with an age range (35-80 years). Research shows the average data of respondents encountered 150 respondents. There are 14 types of medicinal plants used in Jagalan Village, namely Bingbuluh (Belimbing wuluh), jeih (ginger). Kencur (kencor), Sere (Sirih), Molabek Temulawak), Moereng (Temuireng), Binahong, Meronggih (Kelor), Konyek (turmeric), Mores (Soursop), Jembuh (Guava), Orange Porot (Lime), Kodduk (Noni), Blimbing (Starfruit). Reproduction is divided into two parts, namely asexual and sexual, bingbuluh, merongguh, gembuh, orange porous, mores, codduk, and blimbing including the generative and vegetatf reproduction, jihor, kencor, molabek, moereng, binahong, and konyek including rhizoma reproduction (rhizome, live root) is a stem that grows horizontally in the soil resembling roots and then in sere including artificial vegetative reproduction by grafting and ducking.
\end{abstract}

Keywords: Ethnobotany, Failure, Conservation, Medicinal plants 


\section{Pendahuluan}

Etnobotani berasal dari kata etno (etnis) dan botani. Etno berarti masyarakat adat/kelompok sosial kebudidayaan yang memiliki arti tertentu karena keturunan, adat, agama, bahasa, dan lain sebagainya. Sedangkan Botani adalah tumbuh tumbuhan. Etnobotani adalah interaksi masyarakat setempat dengan lingkungan hidupnya, secara spesifik pada tumbuh tumbuhan serta pengkajian penggunaan tumbuhan sebagai makanan, perlindungan atau rumah, pengobatan, pakaian, perburuan, dan upacara adat. Suatu bidang ilmu yang mempelajari antara masyarakat lokal dan alam lingkungannya mengetahui sistem pengetahuan tentang sumber daya tumbuhan. Dalam rangka menggali pengetahuan lebih baik kepada masyarakat tentang pemanfaatan tumbuhan sebagai obat maka perlu diperkenalkan etnobotani yang berpotensi sebagai obat kepada masyarakat. Penelitian dengan pendekataan ilmu pengetahuan masyarakat tentang tumbuhan obat yang telah banyak dilakukan contohnya yaitu tentang tumbuhan katuk di beberapa masyarakat dan pemanfaatan tumbuhan kelor [1].

Tumbuhan obat adalah tumbuhan yang digunakan sebagai obat, baik yang sengaja ditanam maupun tumbuh liar. Tumbuhan tersebut dimanfaatkan oleh masyarakat untuk jamu dan dijadikan sebagai obat penyembuh penyakit. Tumbuhan obat adalah satu di antara bahan utama produk-produk jamu. Bahan tersebut yang masih sederhana, murni, belum tercampur atau belum di olah [2].

Reproduksi merupakan perkembangan penting dalam siklus hidup tanaman yang lebih tinggi, untuk memungkinkan gen induk yang diturunkan ke generasi berikutnya. Reproduksi merupakan salah satu ciri makhluk hidup. Pada dasarnya dalam reproduksi terkandung prinsip "pertambahan jumlah", reproduksi berperan besar dalam mempertahankan spesies agar ada di permukaan bumi dan tidak punah. Namun adanya kendala atau hambatan dalam hal reproduksi akan mengalami kepunahan. Tumbuhan yang punah saat ini, sebagian besar mengalami masalah dalam reproduksi atau hambatan dalam mempertahankan diri mereka dari faktor-faktor ekstrinsik yang kurang menguntungkan [3].

\section{Material dan Metode}

\section{Bahan dan Alat}

Bahan yang digunakan adalah dokumen atau laporan, literatur serta keterangan yang ada di Desa Jagalan Kecamatan Kwanyar Kabupaten Bangkalan. Alat digunakan sebagai berikut: kamera digital, alat perekam suara, alat tulis menulis, laptop.

\section{Metode}

Jenis penelitian ini adalah penelitian deskriptif dengan metode kualitatif. Penelitian Deskriptif yaitu memusatkan perhatian pada masalah-masalah yang ada pada saat penelitian dilakukan (saat sekarang) atau masalah yang bersifat aktual dan menggambarkan fakta-fakta tentang masalah yang diselidiki sebagaimana adanya diiringi dengan interpretasi rasional. Metode kualitatif digunakan untuk mengetahui penggunaan tumbuhan berkhasiat obat yang digunakan di Desa Jagalan dengan wawancara secara langsung.

\section{Hasil dan Diskusi}

\section{Hasil Deskripsi Tumbuhan yang Dimanfaatkan Sebagai Obat}

Dari hasil penelitian terdapat 14 jenis tumbuhan obat yang di manfaatkan di Desa Jagalan, yaitu Bingbuluh (Belimbing wuluh), jeih (jahe), Kencur (kencor), Sere (Sirih), Molabek (Temulawak), Moereng (temuireng), Binahong, Meronggih (Kelor), Konyek (kunyit), Mores (Sirsak), Jembuh (Jambu biji), Jeruk Porot (Jeruk nipis), Kodduk (Mengkudu), Blimbing (Belimbing). Pada Tabel di bawah ini 
e-Jurnal Ilmiah BIOSAINTROPIS (BIOSCIENCE-TROPIC)

Volume 7/ No.: 2 / Halaman 1 - 8 / Januari Tahun 2022

ISSN : 2460-9455 (e) - 2338-2805(p)

akan menjelaskan bahwa Belimbing wuluh tergolong Familia Oxalidaceae, Jahe tergolong familia Zingiberaceae, kencur tergolong familia Zingiberaceae, sirih tergolong familia Piperaceae, temulawak dan temu ireng tergolong familia Zingiberaceae, Binahong tergolong familia Basellaceae, kelor tergolong familia Moringaceae, kunyit tergolong familia Zingiberaceae, sirsak tergolong familia Annonaceae, Jambu biji tergolong familia Myrtaceae, jeruk nipis tergolong familia Rutaceae, mengkudu tergolong familia Rubiaceae dan belimbing tergolong familia Oxalidaceae.

Tabel 1. Deskripsi Tumbuhan Obat

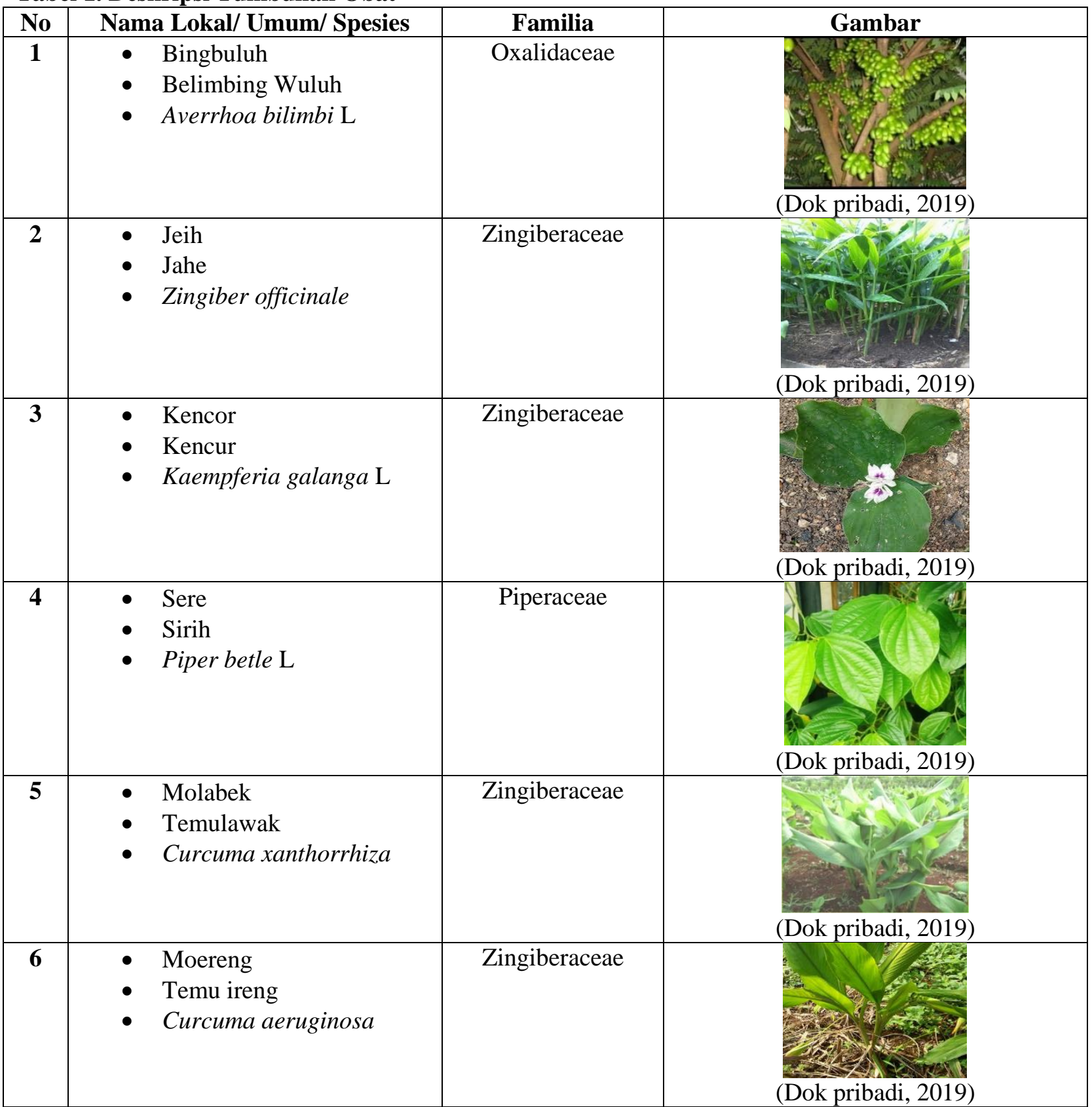


e-Jurnal Ilmiah BIOSAINTROPIS (BIOSCIENCE-TROPIC)

Volume 7/ No.: 2 / Halaman 1 - 8 / Januari Tahun 2022

ISSN : 2460-9455 (e) - 2338-2805(p)

\begin{tabular}{|c|c|c|c|}
\hline 7 & $\begin{array}{l}\text { - } \text { Binahong } \\
\text { - } \quad \text { Binahong } \\
\text { Anredera cordifollia }(\mathrm{Ten})\end{array}$ & Basellaceae & 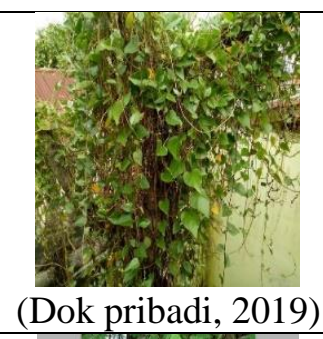 \\
\hline 8 & $\begin{array}{ll}- & \text { Meronggih } \\
- & \text { Kelor } \\
- & \text { Moringa oleifera } \mathrm{L}\end{array}$ & Moringaceae & (Dok pribadi, 2019) \\
\hline 9 & $\begin{array}{ll}\text { - } & \text { Konyek } \\
\text { - } & \text { Kunyit } \\
\text { - } & \text { Curcuma domestica Val }\end{array}$ & Zingiberaceae & (Dok pribadi, 2019) \\
\hline 10 & $\begin{array}{l}\text { - } \text { Mores } \\
\text { - } \quad \text { Sirsak } \\
\text { - Annona muricata L }\end{array}$ & Annonaceae & 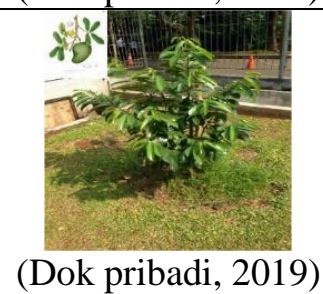 \\
\hline 11 & $\begin{array}{ll}\text { - } & \text { Jembuh } \\
\text { - } & \text { Jambu biji } \\
\text { - } & \text { Psidium guajava }\end{array}$ & Myrtaceae & 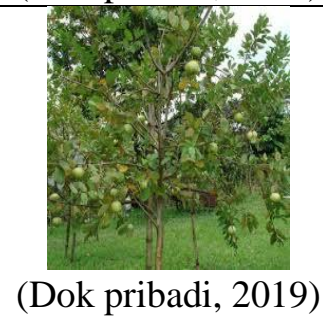 \\
\hline 12 & $\begin{array}{ll}\text { - } & \text { Jeruk porot } \\
\text { - } & \text { Jeruk nipis } \\
\text { - } & \text { Citrus aurantiifolia }\end{array}$ & Rutaceae & (Dok pribadi, 2019) \\
\hline 13 & $\begin{array}{ll}\text { - } & \text { Koddduk } \\
\text { - } & \text { Mengkudu } \\
\text { - } & \text { Morinda citriffolia }\end{array}$ & Rubiaceae & $\begin{array}{c}\text { A prist } \\
\text { (Dok pribadi, 2019) }\end{array}$ \\
\hline
\end{tabular}


e-Jurnal Ilmiah BIOSAINTROPIS (BIOSCIENCE-TROPIC)

Volume 7/ No.: 2 / Halaman 1 - 8 / Januari Tahun 2022

ISSN : 2460-9455 (e) - 2338-2805(p)

\begin{tabular}{|l|l|l|r|}
\hline 14 & $\bullet$ & Blimbing & Oxalidaceae \\
& $\bullet$ Belimbing & \\
& & & \\
\hline
\end{tabular}

\section{Persepsi Pemanfaatan Tumbuhan Obat dan Cara Reproduksi pada Tumbuhan obat masyarakat di Desa Jagalan}

Pada (Gambar 1) ini akan menjelaskan bahwa persentase (\%) dari pemanfatan tumbuhan sebagai obat berdasarkan masyarakat Jagalan ini antara lain adalah : Belimbing $10 \%$, Jahe $10 \%$, Kencur $8 \%$, Sirih $8 \%$, Temulawak 7\%, Temu ireng 7\%, Binahong 8\%, Kelor 3\%, Kunyit 9\%, Sirsak 4\%, Jambu biji $4 \%$, Jeruk Nipis 5\%, Mengkudu 6\% dan Belimbing $2 \%$.

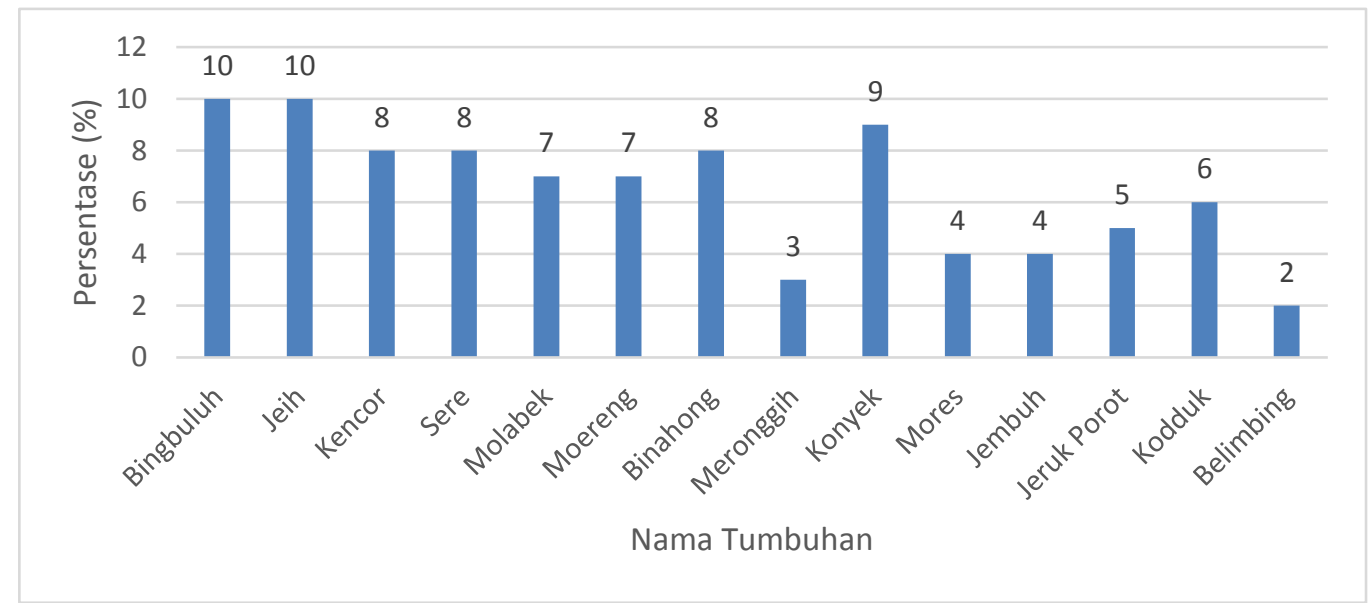

Gambar 1. Persentase jenis tumbuhan sebagai obat oleh masyarakat Jagalan

Tabel 2. Hasil Persepsi Pemanfaatan Tumbuhan Obat

\begin{tabular}{|c|l|l|l|}
\hline No & Nama Spesies & \multicolumn{1}{|c|}{ Cara Pemakaian } & Cara Reproduksi \\
\hline 1 & $\begin{array}{l}\text { Belimbing } \\
\text { Wuluh }\end{array}$ & $\begin{array}{l}\text { Bunganya dibersihkan terlebih dahulu } \\
\text { kemudian ditumbuk, ditambahkan air setelah } \\
\text { itu di peras dan di minum. }\end{array}$ & Generatif dan Vegetatif \\
\hline 2 & Jahe & $\begin{array}{l}\text { Dikupas kulitnya, di cuci kemudian diparut } \\
\text { ditambahkan air dan di peras lalu diminum. }\end{array}$ & $\begin{array}{l}\text { Rhizoma (akar tinggal / } \\
\text { rimpang) }\end{array}$ \\
\hline 3 & Kencur & $\begin{array}{l}\text { Dikupas kulitnya, di cuci kemudian ditumbuk } \\
\text { ditambahkan air dan di peras lalu diminum. }\end{array}$ & $\begin{array}{l}\text { Rhizoma (akar tinggal / } \\
\text { rimpang) }\end{array}$ \\
\hline 4 & Sirih & $\begin{array}{l}\text { Di cuci daunnya terus di tumbuk tambahkan } \\
\text { air dan diperas lalu di minum, sedangkan pada } \\
\text { sakit mata di teteskan airnya. }\end{array}$ & Vegetatif buatan \\
\hline 5 & Temulawak & $\begin{array}{l}\text { Dikupas kulitnya, di cuci kemudian ditumbuk } \\
\text { ditambahkan air dan di peras lalu diminum. }\end{array}$ & $\begin{array}{l}\text { Rhizoma (akar tinggal / } \\
\text { rimpang) }\end{array}$ \\
\hline 6 & Temu ireng & $\begin{array}{l}\text { Dikupas kulitnya, di cuci kemudian ditumbuk } \\
\text { ditambahkan air dan di peras lalu diminum. }\end{array}$ & $\begin{array}{l}\text { Rhizoma (akar tinggal / } \\
\text { rimpang) }\end{array}$ \\
\hline
\end{tabular}


e-Jurnal Ilmiah BIOSAINTROPIS (BIOSCIENCE-TROPIC)

Volume 7/ No.: 2 / Halaman 1 - 8 / Januari Tahun 2022

ISSN : 2460-9455 (e) - 2338-2805(p)

\begin{tabular}{|c|l|l|l|}
\hline 7 & Binahong & $\begin{array}{l}\text { Di cuci daunnya terus di tumbuk tambahkan } \\
\text { air dan diperas lalu di minum, sedangkan pada } \\
\text { luka di tempelkan. }\end{array}$ & $\begin{array}{l}\text { Rhizoma (akar tinggal / } \\
\text { rimpang) }\end{array}$ \\
\hline 8 & Kelor & $\begin{array}{l}\text { Di cuci daunnya terus tambahkan air lalu di } \\
\text { rebus kemudian di minum. }\end{array}$ & Generatif dan Vegetatif \\
\hline 9 & Kunyit & $\begin{array}{l}\text { Dikupas kulitnya, di cuci kemudian ditumbuk } \\
\text { ditambahkan air dan di peras lalu diminum. }\end{array}$ & $\begin{array}{l}\text { Rhizoma (akar tinggal / } \\
\text { rimpang) }\end{array}$ \\
\hline 10 & Sirsak & $\begin{array}{l}\text { Dicuci daunnya lalu di rebus dan di minum } \\
\text { airnya }\end{array}$ & Generatif dan Vegetatif \\
\hline 11 & Jambu biji & $\begin{array}{l}\text { Dicuci daunnya lalu ditumbuk tambahkan air } \\
\text { lalu di peras dan di rebus kemudian di minum. }\end{array}$ & Generatif dan Vegetatif \\
\hline 12 & Jeruk nipis & $\begin{array}{l}\text { Di cuci buahnya lalu di peras dan minum } \\
\text { airnya. }\end{array}$ & Generatif dan Vegetatif \\
\hline 13 & Mengkudu & $\begin{array}{l}\text { Dicuci buahnya lalu di rebus dan di minum } \\
\text { airnya }\end{array}$ & Generatif dan Vegetatif \\
\hline 14 & Belimbing & $\begin{array}{l}\text { Buah yang matang di cuci kemudian di makan } \\
\text { Generatif dan Vegetatif }\end{array}$ \\
\hline
\end{tabular}

Pada penelitian ini terdapat 150 responden yang di wawancarai merupakan ahli pengobatan

responden yang mengetahui tumbuhan berkhasiat obat sebagai informan kunci. Hal ini karena responden tersebut dianggap memiliki pengetahuan yang lebih terkait tumbuhan berkhasiat obat yang mereka gunakan untuk menyembuhakan penyakit. Setiap responden memiliki cara tersendiri dalam penggunaan tumbuhan berkhasiat obat untuk menyembuhkan berbagai jenis-jenis penyakit dan ada cara pengunaannya mereka dapatkan dari ahli pengobatan yang mereka datangi untuk berobat dan ada informasi yang didapat secara turun temurun.

Menurut masyarakat Jagalan tumbuhan yang dapat digunakan sebagai obat perlu diberikan penjelasan mengenai penyakit. Kepercayaan yang berkembang di masyarakat membagi penyakit menjadi tiga jenis, yaitu penyakit biasa, penyakit karena magis dan penyakit karena makanan. Penyakit biasa adalah penyakit yang umum diderita oleh penduduk seperti demam, batuk, sakit badan dan sakit kepala yang timbul akibat perubahan cuaca atau kuman penyakit. Penyakit karena magis diyakini oleh penduduk timbul akibat pelanggaran tata cara hidup di alam seperti halnya penyakit gila, ayan atau lumpuh. Menurut mereka terdapat tiga bentuk pengobatan yang digunakan oleh penduduk untuk mengobati penyakit yaitu tatangkalan atau pengobatan dengan tumbuhan, obat warung, dan jampe. Untuk mengobati penyakit biasa, sebagian penduduk masih menggunakan tumbuhan obat walaupun sebagian sudah beralih pada penggunaan obat warung. Namun demikian penduduk masih mengetahui berbagai macam tumbuhan untuk pengobatan. Pengetahuan masyarakat tentang pemanfaatan tumbuhan sebagai obat perlu diperbaiki dengan menggunakan penjelasan yang lebih rasional dan ilmiah.

Menurut masyarakat Desa Jagalan konyek, molabek, moereng merupakan tumbuhan yang paling sering di gunakan oleh masyarakat di Desa Jagalan untuk pengobatan. Ada 12 kategori penyakit yang di obati dengan memanfaatkan tumbuhan sebagai obat. Penyakit-penyakit yang sering disembuhkan dengan memanfaatkan hewan adalah: batuk, pilek, sakit mata, obat luka, kolestrol, darah tinggi, meredakan panas dalam, stroke, darah tinggi dan kurang nafsu makan dan diare. Dari beberapa penyakit tersebut, penyakit batuk sangat banyak dalam pemanfaatan biodiversitas dari tumbuhan untuk pengobatan yaitu: jeruk porot dan bingbuluh. Informasi yang di dapatkan di Desa Jagalan bahwa tumbuhan obat sangat banyak sekali khasiatnya. Telah di laporkan bahwa pemanfaatan tumbuhan selain sebagai obat juga sebagai bahan makanan. tumbuhan tersebut antara lain: meronggih, jeruk porot, bingbuluh merupakan tumbuhan yang bisa di manfaatkan sebagai makanan. Hal ini menandakan bahwa pentingnya biodiversitas sebagai sumber dari pengobatan dan produk nutrisi, penguatan kebijakan di butuhkan untuk penggunaan biodiversitas secara berkelanjutan. Pemanfaatan tumbuhan sebagai obat di Desa Jagalan masih di lakukan karena masyarakat di Desa Jagalan ini sangat mempercayai tumbuhan obat secara turun temurun. 
Reproduksi tumbuhan dapat dibedakan menjadi 2 yaitu reproduksi aseksual (vegetatif) dan reproduksi seksual (generatif). Reproduksi aseksual/vegetatif merupakan cara reproduksi (perbanyakan diri) tanpa melewati proses peleburan dua gamet. Artinya, satu induk tumbuhan dapat memperbanyak diri menghasilkan keturunan yang memiliki sifat identik dengan induk. Reproduksi vegetatif dapat terjadi secara alami dan buatan (artifisial). Reproduksi vegetatif alami merupakan cara perbanyakan yang dilakukan tumbuhan tanpa melibatkan bantuan manusia. Berikut ini beberapa bagian tumbuhan yang berperan dalam reproduksi vegetatif alami antara lain yaitu rhizoma, stolon, umbi lapis, tunas, umbi batang, dan daun. Sedangkan pada reproduksi vegetatif buatan merupakan cara perbanyakan tumbuhan yang sengaja dilakukan oleh manusia. Dalam hal ini, manusia sengaja memanfaatkan kemampuan meristematis tumbuhan untuk menghasilkan lebih banyak keturunan. Cara perbanyakan ini dapat dilakukan dalam waktu relatif lebih singkat dibandingkan dengan secara alami. Beberapa usaha perbanyakan yang tergolong pada reproduksi vegetatif buatan adalah mencangkok, menempel (okulasi), menyambung, menyetek, merunduk.

Bingbuluh, meronggih, jembuh, jeruk porot,mores, kodduk, dan blimbing reproduksi generatif pada tumbuhan didahului dengan penyerbukan kemudian diikuti dengan peleburan antara sperma dan ovum atau sel telur yang selanjutnya berkembang menjadi individu baru. Sedangkan reproduksi vegetatif pada tumbuhan dilakukan melalui pembentukan individu baru dari bagian tubuh induknya yang kemudian memisahkan diri dari induknya dan menjadi individu baru. Secara generatif tumbuhan ini berkembang biak dengan menggunakan biji. Secara vegetatif tumbuhan ini berkembang biak dengan cara mencangkok (goote). Mencangkok adalah cara perkembangbiakan dengan membuang sebagian kulit dan kambium secara melingkar pada cabang batang, lalu ditutup dengan tanah yang kemudian dibalut dengan sabut atau plastik dan disiram secara teratur. Setelah akar tumbuh, batang dibawah tempat cangkokan dipotong kemudian ditanam. Jeih, kencor, molabek, moereng, binahong, dan konyek termasuk reproduksi rhizoma (rimpang, akar tinggal) merupakan batang yang tumbuh menjalar secara horizontal di dalam tanah menyerupai akar. Sere termasuk pada reproduksi vegetatif buatan yang dengan cara mencangkok dilaksanakan dengan memilih cabang pada tanaman sirih yang sudah tua. Selanjutnya batang tadi diikat dengan dibalut dengan sabut kelapa. Pencangkokkan pada sirih tidak memerlukan tindakan pengupasan pada kulit, meski begitu harus selalu dipastikan induk cangkok dalam keadaan basah agar akar lebih cepat tumbuh. Dengan cara merunduk, cabang tanaman sirih yang sudah cukup umur dirundukkan pada tanah atau medium tanam lainnya hingga akarnya tumbuh.

\section{Kesimpulan (Jika ingin dipisah dari Hasil dan Diskusi)}

Dari hasil penelitian dapat disimpulkan bahwa terdapat 14 jenis tumbuhan yang dijadikan obat di Desa Jagalan, yaitu Bingbuluh (Belimbing wuluh), jeih (jahe). Kencur (kencor), Sere (Sirih), Molabek (Temulawak), Moereng (Temuireng), Binahong, Meronggih (Kelor), Konyek (kunyit), Mores (Sirsak), Jembuh (Jambu biji), Jeruk Porot (Jeruk nipis), Kodduk (Mengkudu) dan belimbing. Pemanfaatannya yaitu untuk menyembuhkan penyakit yang diderita oleh masyarakat Desa Jagalan antara lain batuk, pilek, sakit mata, obat luka, kolestrol, darah tinggi, meredakan panas dalam, stroke, kurang nafsu makan, diare dan darah tinggi. Reproduksi dibagi menjadi dua bagian yaitu aseksual dan seksual, bingbuluh, meronggih, jembuh, jeruk porot,mores, kodduk, dan blimbing termasuk pada reproduksi generative dan vegetatf, jeih, kencor, molabek, moereng, binahong, dan konyek termasuk reproduksi rhizoma (rimpang, akar tinggal) merupakan batang yang tumbuh menjalar secara horizontal di dalam tanah menyerupai akar dan kemudian pada sere termasuk pada reproduksi vegetatif buatan yang dengan cara mencangkok dan merunduk. 
e-Jurnal Ilmiah BIOSAINTROPIS (BIOSCIENCE-TROPIC)

Volume 7/ No.: 2 / Halaman 1 - 8 / Januari Tahun 2022

ISSN : 2460-9455 (e) - 2338-2805(p)

\section{Daftar Pustaka}

[1] Bodeker, G. 2000. Indegenous Medical Knowledne: The Law and Politics of Protections:Oxfond Intellectual Property ResearchCentre Seminar St. Peter's College.

[2] Dalimarta. Kajian Etnobotani TumbuhanRitual Suku Tajio di Desa Kasimbar Kabupaten Parigi Mouton “Jurnal Of Natural Secience. Vol 2 (2) (agustus 1999).

[3] Hayati, A., Arumingtyas, E.L., Indriyani, S. and Hakim, L. 2016. Local Knowladge of Katuk (Sauropus androgynus (L.) Merr) in East Java, Indonesia. International Journal of Current Pharmaceutical Review and Research : 7 (4) : $210-215$

[4] Hayati, A. Fitri, \& Zayadi, H. 2018. Etnobotani Delima (Punica granatum L) di Desa Gulbung Kecamatan Pangarengan Kabupaten Sampang. E-jurnal BIOSAINTROPIS (BIOSCIENCETROPIC). Vol. 3. No. 3. Hal. 39-45. Januari 2018.

[5] Rifai, MA. 1989. Landasan Citra dan Jatidiri Kebun Indonesia: Pengaruh Dari Tamadun Timur. ASRI, Majalah Interior, Taman \& Lingkungan. 76: 34-35.

[6] Purwanto. "Peran dan Peluang Etnobotani Masa Kini di Indinesia Dalam Menunjang Upaya Konservasi dan Perkembangan Keanekaragaman Hayati”. (Prosising Seminar Hasil-Hasil Penelitian Bidang Ilmu Hayat, Labolatorium Etnobotani-Puslitbang-LIPI, Bogor, 1999). 